\title{
Cytogenetical characterization of hatchery stocks and natural populations of Sea and Brown Trout from northwestern Spain
}

\author{
P. MARTÍNEZ, A. VIÑAS, C. BOUZA, J. ARIAS, R. AMARO \& L. SÁNCHEZ \\ Departamento de Biología Fundamental, Area de Genética, Universidad de Santiago, 27002 Lugo, Spain
}

\begin{abstract}
A karyotypic analysis was carried out using conventional staining and banding techniques in Brown Trout and Sea Trout. An important variation in the number of chromosome arms (NF), but not in chromosome number was demonstrated. This wide polymorphism is due essentially to the variation in the short arm of the Nuclear Organizer Region (NOR)-bearing chromosome number 11, which can be used as a population marker. Duplications and triplications of the NOR region are responsible for this variation. The number of NORs per genome are also variable between individuals in a high frequency. $\mathrm{C}$-band polymorphism of the short arms of chromosome pairs 8 and 9 was also demonstrated.
\end{abstract}

Keywords: Brown and Sea Trout, karyotype analysis, NOR and C-band polymorphism.

\section{Introduction}

In common with others salmonids, Salmo trutta exhibits a considerable variability both at the ecological and at the geographical level. The prodigious output of papers dealing with the taxonomy of multitudes of diverse forms in Salmo trutta is a good reflection of it. It is common in the European literature to recognize three basic ecological forms of this species, namely anadromous, lacustrine and fluviatile (trutta, lacustris and fario respectively), which are usually treated as morphae to avoid confusion with geographical subspecies (Behnke, 1972; Capanna et al., 1973). There is little information, however, about the relative contribution of genetic and environmental components to these morphological and behavioural differences.

Some authors, using electrophoretic analysis, have demonstrated a genetic basis for the variation found between certain ecological forms and sympatric populations in Salmo trutta (Ferguson \& Mason, 1981; Ryman et al., 1979). On the other hand, few karyotipic studies have been performed on this populational perspective. The majority have emphasized the possible existence of intra- and interindividual polymorphism in chromosome and arm numbers in relation to the tetraploid origin of salmonids in the process of diploidization (Zenzes \& Voiculescu, 1975; Hartley and Horne, 1984), but little attention has been paid to the differen-

Correspondence: Dr. L. Sánchez, Departamento de Biología Fundamental, Area de Genética, Universidad de Santiago, 27002 Lugo, Spain. tiation between geographical or ecological forms; the chromosome images and sample sizes in these studies did not permit a precise analysis of the variation found. Taking into account the important chromosome polymorphism detected within and between populations in salmonids fish (Hartley \& Horne, 1984; Hartley, 1987), more stringent cytogenetic studies could be useful to distinguish different populations or morphae. In this sense, we have tried to ascertain the possible differentiation between Brown and Sea Trout (fario and trutta, respectively) from a cytogenetic point of view.

\section{Materials and methods}

\section{Population sample}

Fourteen Sea Trout and 19 Brown Trout individuals were sampled. All individuals of Sea Trout and those of Brown Trout from natural populations were sampled from several rivers in Galicia (northwestern Spain) using electrofishing. Brown Trout of hatchery origin were taken from one stock used for repopulation in this region.

\section{Cell culture}

Chromosomes were prepared from lymphocyte cultures. Blood (3-4 ml) was collected from the dorsal vein of the fish previously anaesthetized with MS222. The blood was diluted 1:1 in Hanks balanced salt solu- 
tion (HBSS) and centrifuged at $40 \mathrm{~g}$ for $5 \mathrm{~min}$ at $4^{\circ} \mathrm{C}$. The lymphocyte-rich plasma was centrifuged at $100 \mathrm{~g}$ for $10 \mathrm{~min}$ at $4^{\circ} \mathrm{C}$. The serum was eliminated. The cells were resuspended and washed twice in HBSS and centrifuged at $100 \mathrm{~g}$ for $10 \mathrm{~min}$ at $8^{\circ} \mathrm{C}$. Concentrated cells were inoculated into $3 \mathrm{ml}$ of RPMI 1640 Media (Dutch modification) supplemented with $20 \%$ of fetal calf serum, $0.29 \mathrm{mg} \mathrm{ml}^{-1} \mathrm{~L}$-glutamine, $50 \mathrm{U} \mathrm{ml}^{-1}$ penicillin, $50 \mu \mathrm{g} \mathrm{ml}^{-1}$ streptomycin and $1 \%$ purified phytohaemegglutinin (PHA-P) or 1\% LPS. Cultures were incubated at $19^{\circ} \mathrm{C}$ for 5 days. Colchicine was added to a final concentration of $0.0125 \mu \mathrm{g} \mathrm{ml}^{-1} 4-5 \mathrm{~h}$ before harvesting. Cells were incubated in $0.075 \mathrm{M} \mathrm{KCl}$ at room temperature for $15 \mathrm{~min}$ and fixed in methanol:acetic $3: 1$, washed twice in fixative and finally spread onto cleaned slides.

\section{C-banding}

Slides were incubated in $0.2 \mathrm{~N} \mathrm{HCl}$ for $50 \mathrm{~min}$, dipped into saturated $\mathrm{Ba}(\mathrm{OH})_{2}$ at $37^{\circ} \mathrm{C}$ for $30 \mathrm{~s}$ to $1 \mathrm{~min}$ and incubated in $2 \times \mathrm{SSC}$ at $60^{\circ} \mathrm{C}$ for $1 \mathrm{~h}$ and $15 \mathrm{~min}$. Slides were stained in $10 \%$ Giemsa for $10-15 \mathrm{~min}$.

\section{NOR silver staining}

Treatment was performed according to Howell \& Black (1980) with slight modifications. After treatment with the $\mathrm{AgNO}_{3}$ mixture, the slides were incubated in a sodium thiosulphate solution $(5 \% \mathrm{w} / \mathrm{v})$ for $30 \mathrm{~s}$ and washed in distilled water and stained in $3 \%$ Giemsa for 5 min.

\section{CMA3 staining}

The methodology developed by Schweizer (1976, 1980) was applied.

\section{Chromosome counting}

A total of 526 metaphases from the 33 individuals sampled was analysed for chromosome counting and the better defined 227 were selected to determine the number of chromosome arms. The NF value was estimated by computing the uniarmed (acrocentric and subtelocentric) and biarmed chromosomes (metacentric and submetacentric) according to the classification of Levan et al. (1964). The submeta/subtelocentric chromosomes in the limit between one or two arms were scored as $1 / 2$ arms.

\section{Results}

No karyotypic differences were detected between Brown and Sea Trout after analysing 33 individuals with conventional staining and banding techniques
(Giemsa, C-, Ag- and CMA3 banding). The karyotypes of Sea Trout, based on these four techniques, are shown in Figs 1-4. Like Brown Trout, Sea Trout exhibits seven pairs of metacentric chromosomes, four pairs of submetacentrics, six pairs of subtelocentrics and 23 pairs of acrocentric chromosomes (Fig. 1). C-bands are mostly centromeric. Some telomeres appear to be faintly stained, and in addition, a few intercalary and C-positive short arms are present (Fig. 2 ). Active NORs are located on the short arms of the submetacentric chromosome pair number 11 and usually show a clear heteropycnosis with Giemsa staining. NOR associations are also frequent. Occasionally a third NOR can appear in one of the subtelocentric chromosomes members of pair 14 (Fig. 3). Chromosome pairs numbers $13,14,15$ and 16 are brightly stained with CMA3 in their centromeres. The entire short arms of the NOR-bearing chromosome (pair II) is equally $\mathrm{CMA}_{3}$ positive. A faint subcentromeric band in pair number 1 is also detectable (Fig. 4).

As can be observed in Table 1, all the individuals analysed from both morphae exhibit the same modal number of 80 chromosomes (more than $50 \%$ of the plates in the whole sample). Metaphases with more than 80 chromosomes were not found. In some plates with lengthened chromosomes, however, spurious counts are possible due to the existence of occasional breakages in the long arms of chromosome pairs 11 and 12 , and the great centromere stretching of some metacentrics. The rupture of these large submeta and subtelocentric pairs makes the heterochromatic association possible between some non-homologue chromosomes (Fig. 5). All plates with less than 80 chromosomes are incomplete since the decrease in the arm number is in accordance with the decrease in chromosome number. The high number of incomplete metaphases (around 20\%) suggests a technical device rather than an aneuploidization mechanism.

The fundamental number was variable between individuals ranging in value from 100 to 102 . This variation is essentially due to the high polymorphic NOR-bearing chromosome pair number 11 , which can appear from acrocentric to metacentric with Giemsa staining, depending on the individual. In addition, chromosome pair number 9 exhibits a heterochromatic variation in its short arm, which determines its classification as submetacentric or submeta/subtelocentric according to individual. The comparison of the mean NF between Sea and Brown Trout (100.9 and 101.1 for Sea and Brown Trout, respectively) does not support the idea of any significant difference between them. Equally the Brown Trout individuals from natural populations are similar to those from hatchery stock. 
Fig. 1 Standard karyotype of Sea Trout (Salmo trutta $\mathrm{m}$. trutta). Two armed chromosomes (metacentrics and submetacentrics) in the first two rows. Uniarmed chromosomes (subtelocentrics and acrocentrics) in the following five rows.

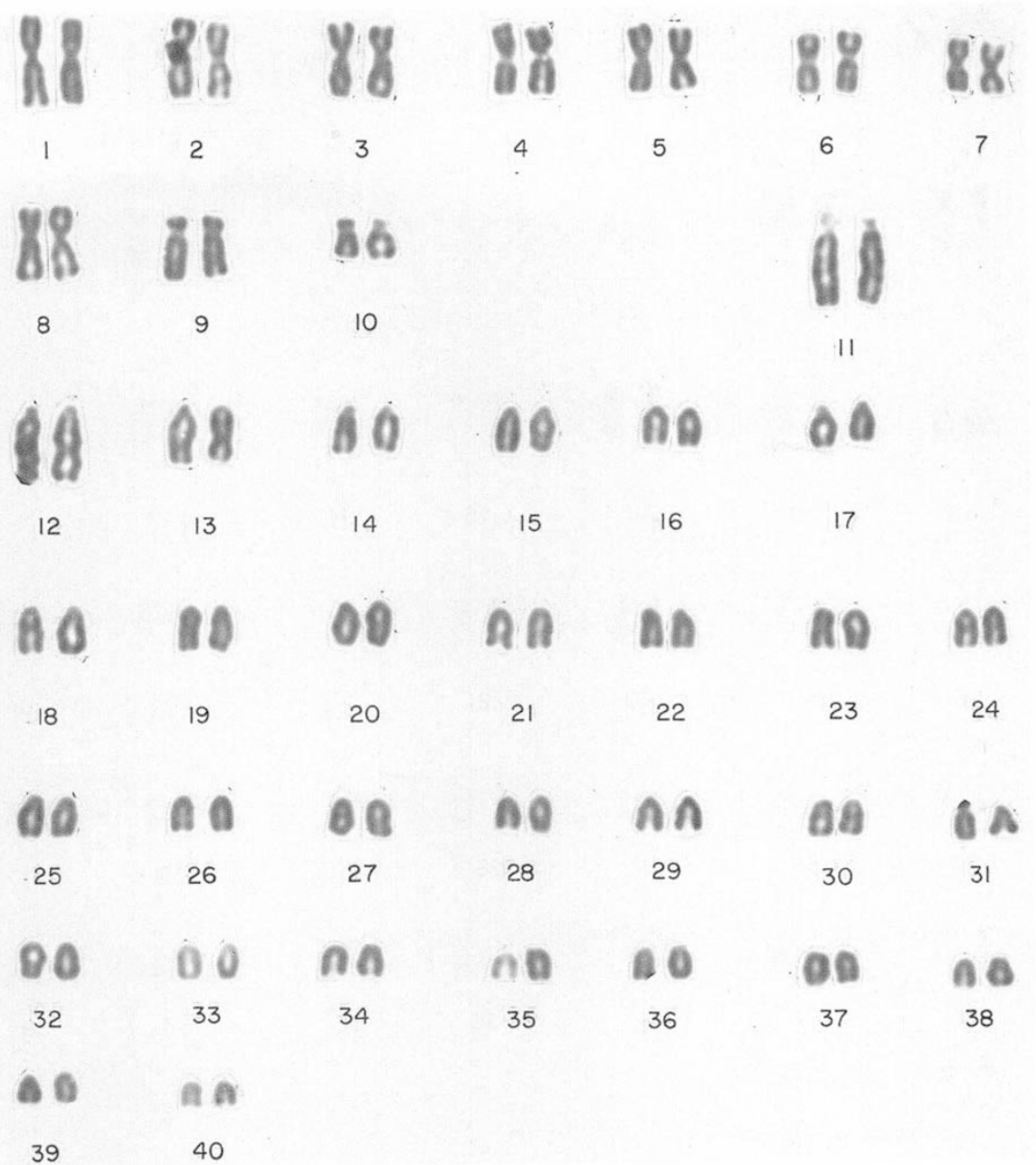

Polymorphism of the NOR-region was detected both in size and number. It was possible to discern chromosomes of five different sizes. This variation is due, at least in part, to NOR duplications and triplications (Fig. 7). Table 1 demonstrates that a high number of heterozygote individuals was detected in the population sampled for this chromosome pair $(69 \%)$. Four out of 11 individuals $(36.9 \%)$ exhibited a third NOR in chromosome pair number 14 , which is CMA3 positive like pair number 11 . This third NOR, however, was not present in all the metaphases analysed except in one individual. A third nucleolus was detected in $2 \%$ of the cells studied but none displayed four nucleoli.

Heterochromatic polymorphism was revealed in the short arms of chromosome pairs 8 and 9 which are C-positive (Fig. 2), and this variation occurs in a similar proportion both in Brown and Sea Trout. It is not possible to match the four chromosomes of these two pairs, at least with the conventional techniques used, and therefore they are arbitrarily matched to take account of the length of their short arm. It is possible, however, to distinguish variable patterns of C-band size even in the four chromosomes when different individuals are compared (Fig. 8).

\section{Discussion}

The striking morphological and ethological differences evidenced by Sea and Brown Trout has led to them being placed in different taxonomic categories. Although in some cases there seems to be a certain spatial segregation between these two morphae (Bagliniere et al., 1989), the lack of reproductive isolation, clearly demonstrated by several authors (Campbell, 1977; Jonsson, 1985), is a sound reason for considering Brown and Sea Trout as members of the same demes. It is evident that there is a genetic basis underlying the mechanism of smoltification in salmonids, but 


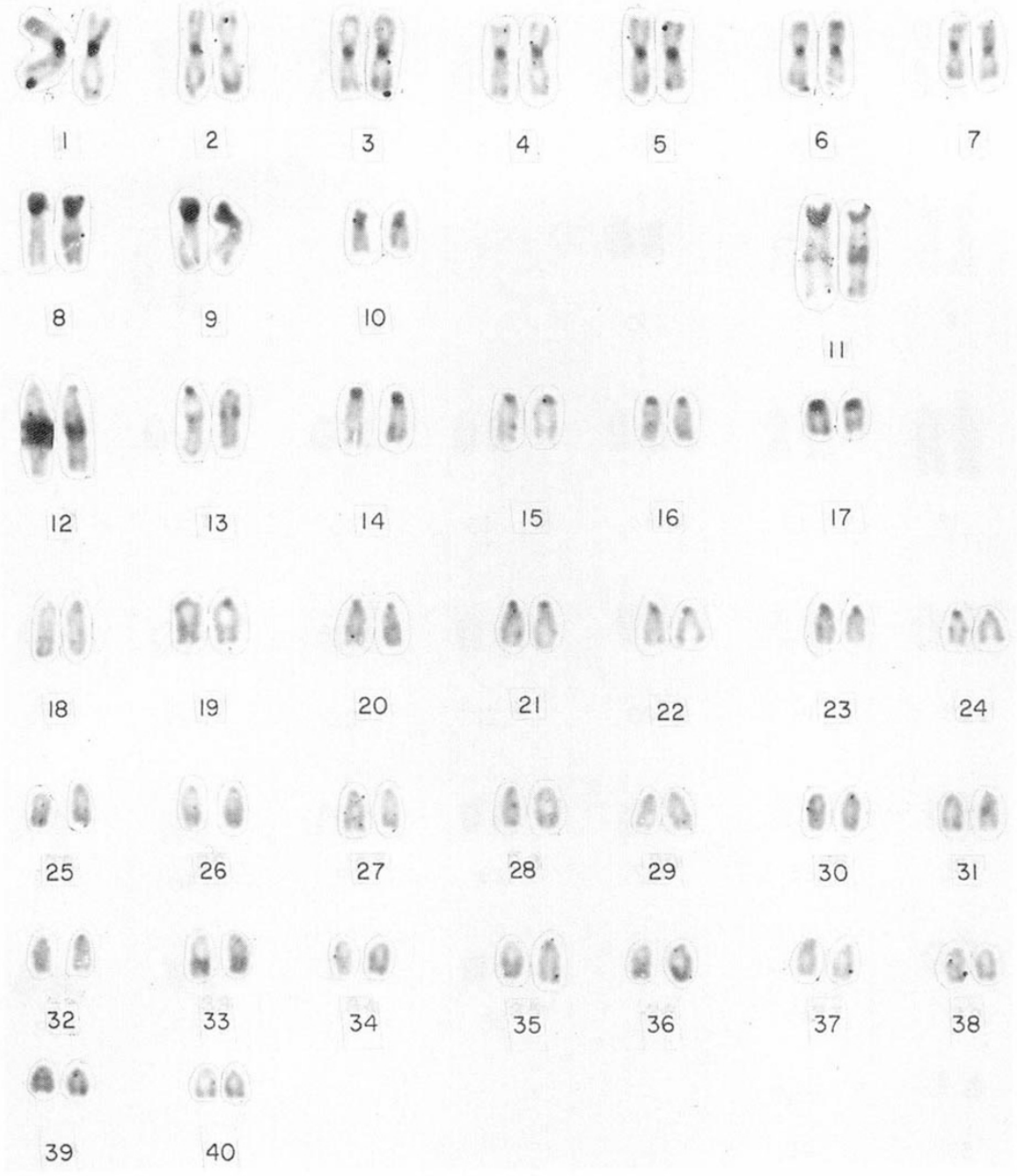

Fig. 2 Standard C-banded karyotype of Sea Trout. the relative genetic or environmental influence in the switching of this process, and the degree of genetic differentiation, if it exists, remains obscure. Thus, Svärdsom \& Fageström (1982) and Jonsson (1982) could check the existence of inherited variation in the trout's tendency to migrate by studying different stocks or populations in this species. On the other hand, the biochemical analysis carried out by Ryman (1983), with several populations of Brown and Sea Trout, revealed the existence of slight genetic differences between these ecological forms. However, the major differentiation shown in this study between the anadromous stocks, with regard to some resident populations, supports the fact that genetic differences underlying the process of smoltification and migration should only affect a small fraction of the whole genome. Few cytogenetic studies have been performed to analyse the degree of chromosome divergence between these ecological forms. Nygren et al. (1971) claimed a high karyotypic similarity between Brown and Sea Trout, but the small sample size and the low quality of the metaphase images managed in this study do not permit any accurate karyotypic comparison. The results obtained in our work confirm the absence of chromosome differentiation between these morphae and indicates that only a slight genetic divergence between Brown and Sea Trout could account for their morphological and ethological differences.

Inter- and intraindividual variation in chromosome number appears to be a widespread phenomenon in salmonid fish (Hartley, 1987). As Ohno (1970) suggests, the tetraploid origin of this group in the process of diploidization is probably on the basis of this polymorphism. However, the variation has been confirmed essentially in those species of salmonids in which there have been extensive fusions in their evolutionary line (chromosome number around 60). In Salmo trutta, and in those species with a chromosome 


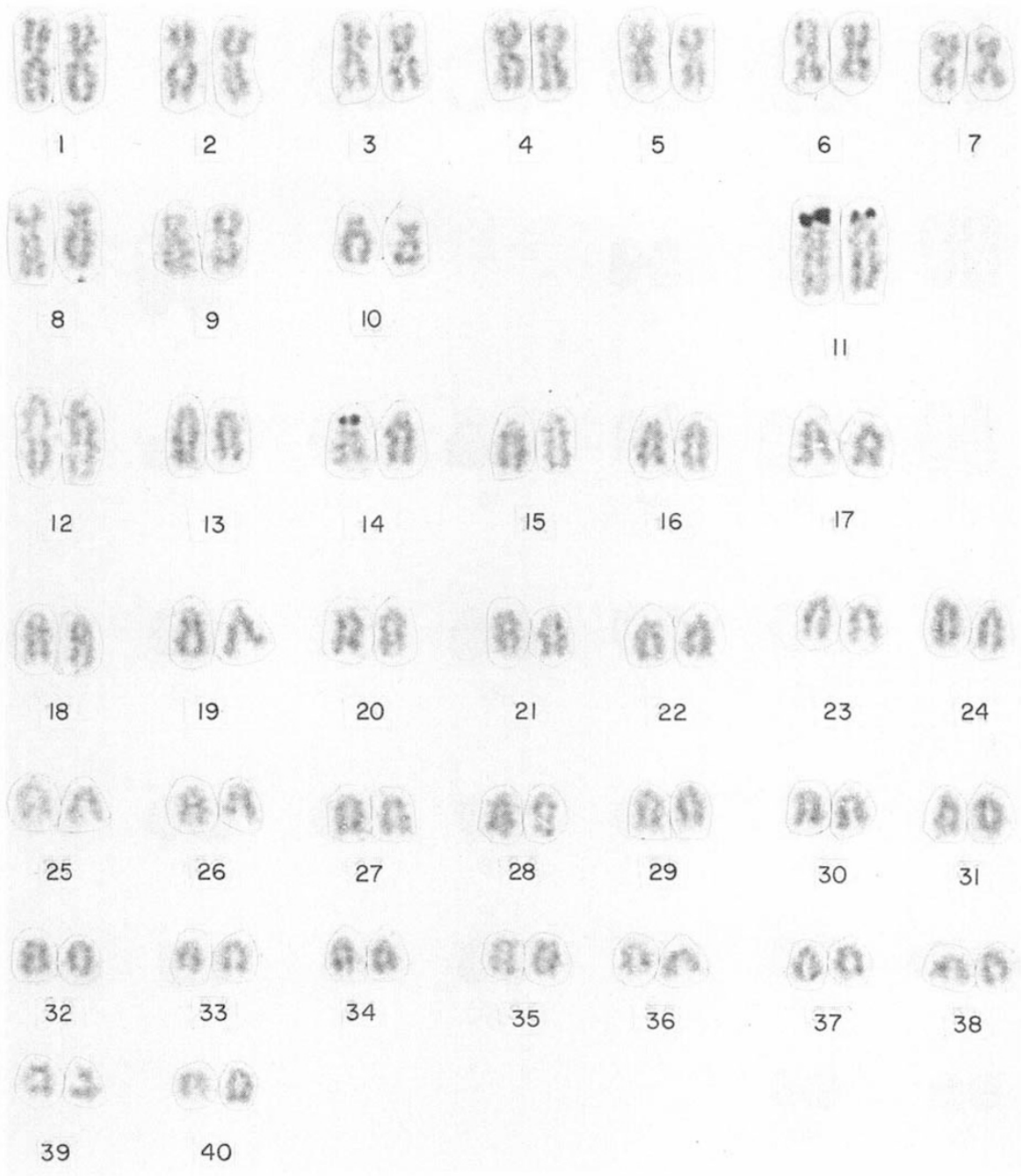

Fig. 3 Standard karyotype of Sea Trout with Ag-NOR staining. Note the third NOR in one of the subtelocentric chromosomes members of pair 14 . number around 80 , this fact is not so evident. So, Zenzes \& Voiculescu (1975) and Hartley \& Horne (1984) described (in some populations of Brown Trout) inter- and intraindividual polymorphism in chromosome number, which could be explained in some cases as Robertsonian translocations because of their constancy in chromosome number (NF). Other authors, however, have not found evidence of such polymorphism in this species (Capanna et al., 1973; Raicu \& Taisescu, 1977; Al-Sabti, 1985), implying that the intraindividual variation is the result of an aneuploidization mechanism or of a technical deficiency. In our work the analysis of a wide sample of metaphases and individuals confirms the absence of a variation in chromosome number in the populations studied.

We have found a polymorphism in NF rather than in the chromosome number (Table 1). The data published on this subject to date reveal a great heterogeneity in $\mathrm{NF}$ according to the authors and the populations analysed. The values range from $\mathrm{NF}=100$ (Nygren et al., 1971; Capanna et al., 1973; Al-Sabti, 1985) to $\mathrm{NF}=104$ (Raicu \& Taisescu, 1977), some authors claiming $\mathrm{NF}=102$ (Zenzes \& Voiculescu, 1975; Hartley \& Horne, 1984). The analysis of the results leads us to suggest the existence of an interindividual and probably interpopulational variation in NF which is essentially due to the polymorphism of the NORbearing chromosome. This can appear as acrocentric in some cases (Capanna et al., 1973; Raicu \& Taisescu, 1977; Al-Sabti, 1985), and as submetacentric-subtelocentric in others (Zenzes \& Voiculescu, 1975; Hartley \& Horne, 1984; Mayr et al., 1986). The populations analysed in our study show a similarity between them, this chromosome pair appearing as submeta or subtelocentric in the majority. The common practice of restocking, followed in this geographical area for more than 20 years, has probably led to the genetic homogeneity of Trout populations. Only one river of the total sampled has not been restocked and the existence of a dam has probably helped to maintain the original 

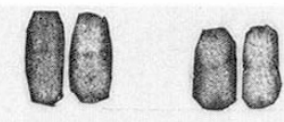

2

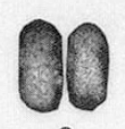

8

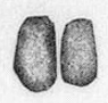

9

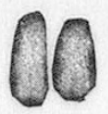

12

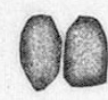

13

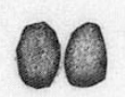

18

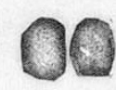

19
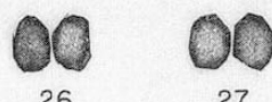

36
27

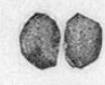

28

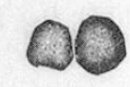

29

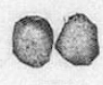

35
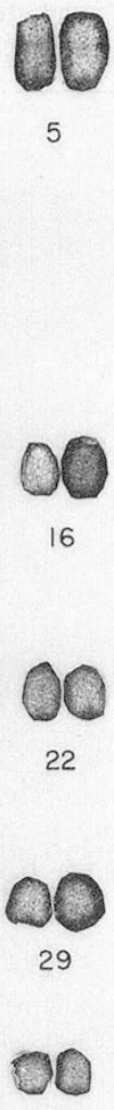

5

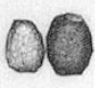

16

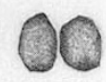

22

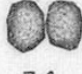

34

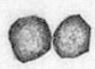

40

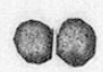

39

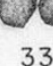

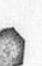

genetic characteristics of this autoctonal population. In fact, the NOR-bearing chromosome appears as acrocentric in the majority of individuals sampled in this river. Therefore, this chromosome pair is a useful population marker. In addition, the small pair of submetacentrics (number 10), pointed out by Hartley (1987), the submetacentric pair number 9, and some of the subtelocentric pairs (from number 13 to 18 ), which could in some cases be classified mistakenly, would account for part of the variation in arm number.

Polymorphism of NOR regions seems to be an important phenomenon in fish and particularly in salmonids (Phillips \& Ihssen, 1985). The variation refers both to the number of active NORs per genome, and to the size and location of these NORs. In Salmo trutta, the NORs are commonly located in the short arm of the chromosome pair number 11 , but a variation in NOR size (Sanchez et al., 1990) and in the number of active NORs per genome (Phillips \& Ihssen, 1985; Mayr et al., 1988) has been reported. In our work we could detect a variation both in size and

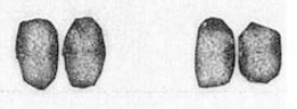

67

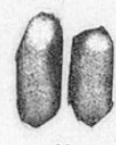

11

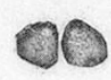

17
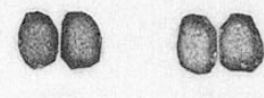

23

24
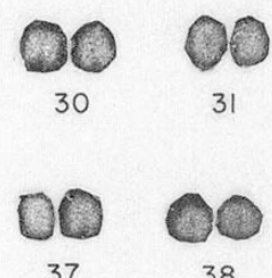

31

37

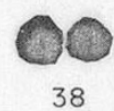

Fig. 4 Standard karyotype of Sea Trout with CMA3 banding. Note the positive staining of the NOR-bearing chromosomes pairs 11 and 14. number. The former is due to duplications and triplications of Ag-NORs, at least partially. We found, with Giemsa staining, five types of NOR chromosomes, ranging from acrocentric to metacentric. This can explain the high number of heterozygote individuals detected $(69 \%)$, which should approach a maximum value of $80 \%$, assuming an equal frequency for each chromosome type

$H=1-\sum_{i=1}^{n} x_{i}^{2}$.

Therefore, it is unnecessary to invoke a postzygotic selection to account for the high heterozygosity level exhibited by this pair, as has been pointed out by Sanchez et al. (1990). Some authors have claimed that the variation in size found between the NOR chromosomes in several species of fish should be more functional than structural, since they could not establish a positive correlation between the different techniques used on this chromosome segment (Sola et al., 1988; Lopez et al., 1989). In Salmo trutta, however, we have 
Table 1 Chromosome number distribution in 33 individuals of Sea and Brown Trout from hatchery stock and natural populations

\begin{tabular}{|c|c|c|c|c|c|c|c|c|}
\hline \multirow[b]{3}{*}{ Fish } & \multirow{3}{*}{$\begin{array}{l}\text { Total } \\
\text { examined }\end{array}$} & \multicolumn{7}{|c|}{ Number of metaphases } \\
\hline & & \multicolumn{5}{|c|}{ Chromosome number } & \multirow[b]{2}{*}{ NF } & \multirow{2}{*}{$\begin{array}{l}\text { NOR-bearing } \\
\text { chromosome }\end{array}$} \\
\hline & & 76 & 77 & 78 & 79 & 80 & & \\
\hline $\mathrm{N}-2.3 \mathrm{~S}$ & 13 & 1 & 3 & - & 1 & $8(2)$ & 100 & Hom. \\
\hline $\mathrm{N}-3.8 \mathrm{~S}$ & 13 & 2 & - & - & $1(1)$ & $7(4)$ & $100 / 102$ & Hom. \\
\hline $\mathrm{N}-4.1 \mathrm{~S}$ & 17 & - & 2 & 2 & 2 & $10(1)$ & $100 / 101$ & Het. \\
\hline $\mathrm{N}-4.2 \mathrm{~S}$ & 20 & - & $1(1)$ & - & $3(1)$ & $15(9)$ & 101 & Het. \\
\hline $\mathrm{N}-4.3 \mathrm{~S}$ & 16 & - & - & 1 & 4 & 10 & $100 / 101$ & Het. \\
\hline $\mathrm{N}-4.4 \mathrm{~S}$ & 26 & 1 & - & $4(1)$ & $8(6)$ & $10(7)$ & $100 / 101$ & Het. \\
\hline $\mathrm{N}-4.5 \mathrm{~S}$ & 10 & - & 1 & 3 & $2(1)$ & $3(1)$ & 101 & Het. \\
\hline $\mathrm{N}-4.6 \mathrm{~S}$ & 8 & - & 1 & 1 & 2 & $4(1)$ & $100 / 101$ & Het. \\
\hline $\mathrm{N}-10.1 \mathrm{~S}$ & 16 & - & 1 & - & $4(2)$ & $8(7)$ & $100 / 102$ & Hom. \\
\hline $\mathrm{N}-10.5 \mathrm{~S}$ & 12 & - & - & 1 & 1 & 10 & 102 & Hom. \\
\hline $\mathrm{N}-10.8 \mathrm{~S}$ & 12 & 1 & 1 & 1 & $1(1)$ & $4(4)$ & 101 & Het. \\
\hline $\mathrm{N}-10.9 \mathrm{~S}$ & 18 & 1 & - & 2 & $2(2)$ & $13(11)$ & $101 / 102$ & Het. \\
\hline $\mathrm{N}-10.10 \mathrm{~S}$ & 14 & - & 1 & $2(1)$ & $1(1)$ & $7(5)$ & $100 / 102$ & Hom. \\
\hline $\mathrm{N}-10.11 \mathrm{~S}$ & 15 & - & 1 & $3(1)$ & $1(1)$ & $8(8)$ & $100 / 102$ & Hom. \\
\hline $\mathrm{N}-1.6 \mathrm{~B}$ & 10 & 1 & - & - & $2(1)$ & $4(2)$ & $100 / 101$ & Het. \\
\hline $\mathrm{N}-1.8 \mathrm{~B}$ & 19 & - & 3 & 5 & $5(2)$ & $6(5)$ & 100 & Hom. \\
\hline N-1.9 B & 17 & - & - & 1 & $6(4)$ & $9(6)$ & 101 & Het. \\
\hline $\mathrm{N}-2.1 \mathrm{~B}$ & 10 & - & 1 & - & - & $8(8)$ & 102 & Het. \\
\hline $\mathrm{N}-2.2 \mathrm{~B}$ & 10 & $1(1)$ & 1 & - & $3(2)$ & $5(4)$ & 102 & Het. \\
\hline $\mathrm{N}-2.5 \mathrm{~B}$ & 28 & 1 & - & - & $7(2)$ & $17(7)$ & 101 & Het. \\
\hline $\mathrm{N}-2.7 \mathrm{~B}$ & 15 & 1 & 2 & $2(2)$ & $2(2)$ & $8(3)$ & $100 / 101$ & Het. \\
\hline $\mathrm{N}-11.3 \mathrm{~B}$ & 9 & - & - & - & $2(2)$ & $7(6)$ & 100 & Hom. \\
\hline P-2.1 B & 25 & 1 & $1(1)$ & 1 & $1(1)$ & $16(8)$ & $101 / 102$ & Het. \\
\hline P-2.2 B & 22 & - & - & - & $1(1)$ & $12(6)$ & 101 & Het. \\
\hline P-2.3 B & 32 & - & - & - & $2(1)$ & $30(9)$ & $100 / 102$ & Hom. \\
\hline P-7.1 B & 20 & - & 4 & 2 & $2(1)$ & $11(8)$ & $100 / 101$ & Het. \\
\hline P-7.3 B & 16 & - & - & 1 & $3(1)$ & $12(8)$ & 101 & Het. \\
\hline P-22.1 B & 9 & 1 & - & $2(1)$ & $1(1)$ & $4(3)$ & $101 / 102$ & Het. \\
\hline P-22.2 B & 11 & - & 2 & 1 & $1(1)$ & $6(5)$ & $101 / 102$ & Het. \\
\hline P-22.3 B & 12 & 2 & 1 & 1 & $2(1)$ & $6(5)$ & $100 / 101$ & Het. \\
\hline P-22.4 B & 19 & 1 & 1 & 1 & $4(2)$ & $6(4)$ & $100 / 102$ & Hom. \\
\hline P-23.1 B & 11 & - & 2 & - & $2(2)$ & $5(3)$ & $101 / 102$ & Het. \\
\hline P-23.4 B & 17 & 2 & 1 & - & $1(1)$ & $8(8)$ & 102 & Het. \\
\hline
\end{tabular}

The numbers in brackets indicate the metaphases analysed for Fundamental Number (NF).

$\mathrm{S}=$ Sea Trout $\mathrm{B}=$ Brown Trout $\mathrm{N}=$ natural population; $\mathrm{P}=$ hatchery stock;

Hom. $=$ homozygote Het $=$ heterozygote .

demonstrated the existence of a positive correlation between Giemsa, Ag, C- and CMA3 banding (Fig. 6), and between different plates within each indvidual, which supports a structural polymorphism rather than a functional one.

Four out of 11 individuals $(36.4 \%)$ were found to possess a third NOR. This frequency is much greater than that reported by Mayr et al. $(1986,1988)$. The use of CMA3 fluorochrome indicates that the third NOR chromosome probably belongs to one of the 14 or 15 subtelocentric pairs (Figs. 3 and 4 ) and is probably the same as that reported by Mayr et al. (1988) and by Phillips \& Hartley (1988) with CMA3. In addition, we found three more subtelocentric chromosome pairs 


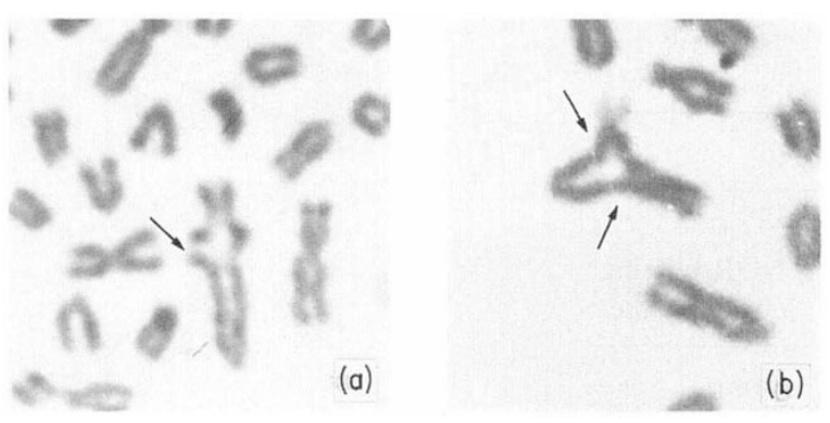

Fig. 5 Particular heterochromatic associations between the large submeta and subtelocentric pairs numbers 11 and 12 and some acrocentrics in Salmo trutta. (a) Heterochromatic centromere-telomere association (arrow); (b) association between intercalary and telomeric heterochromatin. Note the breakage of the long arm of the subtelocentric chromosome (arrows).

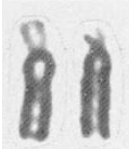

(a)

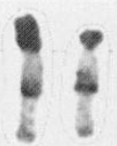

(b)

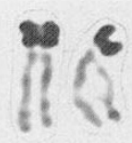

(c)

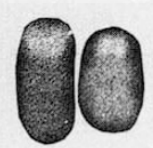

(d)
Fig. 6 Correlation between different stainin and banding techniques in the NOR-bearing chromosome pair number 11 with the same individual in Salmo trutta. (a) Giemsa; (b) C-band; (c) Ag-staining; (d) CMA3 staining.

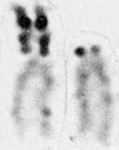

(a)

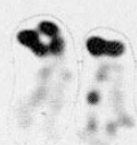

(b)

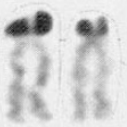

(e)

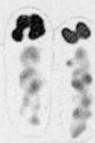

(c)

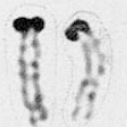

(f)
Fig. 7 Polymorphism of the NOR-bearing chromosome in different individuals of Brown $(a, b, d, f)$ and Sea Trout $(c, e)$ using Ag-staining.

which show CMA3-positive bands in their centromeres (Fig. 4).

Heterochromatin polymorphisms have been widely reported in many species of vertebrate (John \& Miklos, 1979), however in fish, and especially in salmonids, there are few references to such variation. In addition, the polymorphism found in salmonids has been restricted generally to the NOR-bearing chromosomes (Ueda et al., 1985; Hartley, 1988), which are usually $\mathrm{C}$-positive in fish.

In our work we detected an important variation in the C-positive short arms of the chromosome pairs

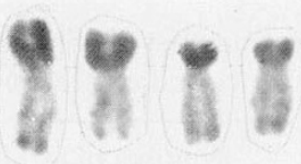

(a)

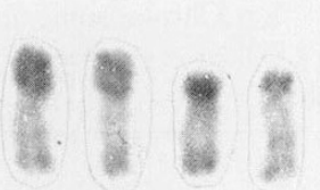

(b)

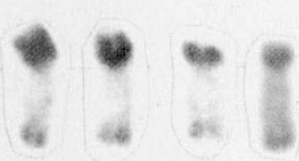

(c)

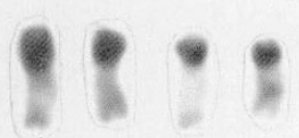

(d)

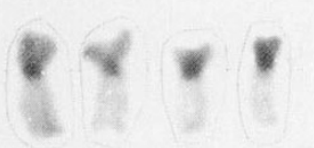

(e)

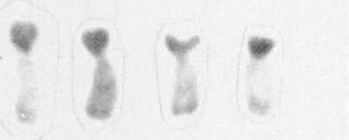

(f)

Fig. 8 C-band polymorphism in the short arm of chromosome pairs 8 and 9 in different individuals of $\operatorname{Brown}(a, b, d)$ and Sea Trout (c, e, f). Chromosomes and individuals are arranged in relation to their $\mathrm{C}$-band size from left to right and from top to bottom respectively.

number 8 and 9 , which are of similar magnitude in the populations sampled. Other studies are being performed to analyse this heterochromatic variation using restriction enzymes.

In this work we demonstrated the absence of chromosome differentiation between Brown and Sea Trout using conventional chromosome treatments. Further studies are necessary to establish the degree of genetic divergence between these ecological forms in salmonids. This would help to clarify their evolutionary relationship and to establish an adequate taxonomic system for their classification. 


\section{Acknowledgements}

This study was supported by the Universidad de Santiago (60902 25022) and Conselleria de Agricultura (Xunta de Galicia). The authors want to thank Dr R. Lozano for technical contributions.

\section{References}

AL-SABTI, K. 1985. Chromosomal studies by blood leukocyte culture technique on three salmonids from Yugoslavian waters. J. Fish. Biol., 26, 5-12.

BAGLiNIERE, J. L., MAISSE, G., LEBAIL, P. Y. AND NIHOUARN, A. 1989. Population dynamics of Brown Trout, Salmo trutta L., in a tributary in Brittany (France): spawning and juveniles. $J$. Fish Biol., 34, 97-110.

BEHNKE, R. J. 1972. The systematics of salmonid fishes of recently glaciated lakes. J. Fish. Res. Bd. Canada, 29, 639-671.

CAMPBELL, J. S. 1977. Spawning characteristics of Brown Trout and Sea Trout Salmo trutta L. in Kirk Burn, River Tweed, Scotland. J. Fish Biol., 11, 217-229.

CAPANNA, E. CATAUdella, S. AND Gentile de FRONZA, T. 1973. Some remarks on the karyotype of an intergeneric hybrid, Salmo trutta $\times$ Salvelinus fontinalis (Pisces: Salmoniforms). Genetica, 44, 194-206.

FERGUSON, A. AND MASON, F. M. 1981. Allozyme evidence for reproductively isolated sympatric populations of Brown Trout Salmo trutta L. in Lough Melvin, Ireland. J. Fish Biol., 18, 629-642.

HARTLEY, S. E. 1987. The chromosomes of salmonid fishes. Biol. Rev., 62, 197-214.

HARTLEY, S. E. 1988. Cytogenetic studies of Atlantic salmon, Salmo salar L., in Scotland, J. Fish Biol., 33, 735-740.

HARTLEY, S. E. AND HORNE, M. T. 1984. Chromosome relationships in the genus Salmo. Chromosoma (Berlin), 90, 229-237.

HOWELL, W. M. AND BLACK, A. 1980. Controlled silver-staining of nucleolus organizer regions with a protective colloidal developer: A 1-step method. Experientia, 36, 1014-1015.

JOHN, B. AND MikLOS, G. L. G. 1979. Functional aspects of satellite DNA and heterochromatin. Inter. Rev. Cytol., 58, 1-114.

JoNsson, B. 1982. Diadromous and resident trout Salmo trutta: is their difference due to genetics? Oikos, 38, 297-300.

JONSSON, B. 1985. Life history patterns of freshwater resident and sea-run migrant brown trout in Norway. Trans. Am. Fish. Soc., 114, 182-194.

LEVAN, A., FREDGA, K. AND SANDBERG, A. A. 1964. Nomenclature for centromeric position on chromosomes. Hereditas, $\mathbf{5 2}$, 201-220.

LOPEZ, J. R., ALVAREZ, M. C., THODE, G. AND MARTINEZ, G. 1989. Karyotype divergence in Symphodus melops and
Symphodus roissali (Labridae, Perciforms): C-banded and Ag-NOR karyotypes. Genome, 32, 35-39.

MAYR, B., KALAT, M. AND RAB, P. 1988. Heterochromatins and band karyotypes in three species of salmonids. Theor. Appl. Genet., 76, 45-53.

MAYR, B., RAB, P. AND KALAT, M. 1986. Localisation of NORs and counterstain-enhanced fluorescence studies in Salmo gairdneri and Salmo trutta (Pisces, Salmonidae). Theor. Appl. Genet., 71, 703-707.

NYGREN, A., NILSSON, B. AND JAHNKE, M. 1971. Cytological studies in Salmo trutta and Salmo alpinus. Hereditas, 67, 259-268.

OHNo, s. 1970. Evolution by Gene Duplication. SpringerVerlag, New York.

PHILliPS, R. B. AND HARTLEY, S. E. 1988. Fluorescent banding patterns of the chromosomes of the genus Salmo. Genome, 30, 193-197.

PHILLIPS, R. B. AND IHSSEN, P. E. 1985. Chromosome banding in salmonid fish: nucleolar organizer regions in Salmo and Salvelinus. Can. J. Genet. Cytol., 27, 433-440.

RAICU, P. AND TAISESCU, E. 1977. Cytogenetic study in Salmo irideus and S. trutta fario. Cytologia, 42, 311-314.

RYMAN, N. 1983. Patterns of distribution of biochemical genetic variation in salmonids: differences between species. Aquaculture, 33, 1-21.

RYMAN, N., ALLENDORF, F. W. AND STÄHL, G. 1979. Reproductive isolation with little genetic divergence in sympatric populations of brown trout (Salmo trutta). Genetics, 92, 247-262.

SANCHEZ, L., MARTINEZ, P., VIÑAS, A. AND BOUZA, C. 1990. Analysis of the structure and variability of nucleolar organizer regions of Salmo trutta by C-, Ag and restriction endonuclease banding. Cytogenet. Cell Genet., 54, (in press).

SCHWEIZER, D. 1976. Reverse fluorescent chromosome banding with Chromomicin and DAPI. Chromosoma, 58, 307-324.

SCHWEIZER, D. 1980. Simultaneous fluorescent staining of $R$ bands specific heterochromatic regions (DA-DAPI bands) in human chromosomes. Cytogenet. Cell Genet., 27, 190-193.

SOlA, L., NATILI, G. L. AND CATAUdElla, s. 1988. Cytogenetical characterization of Odontesthes bonariensis (Pisces, Atherinidae), an Argentine species introduced in Italy. Genetica, 77, 217-224.

SVÄRSON, G. AND FAGERSTROM, A. 1982. Adaptive differences in the long-distance migration of some trout (Salmo trutta L) stocks. Institute of Freshwater Research Drottning-holm Report, 60, 51-80.

UEDA, T., OJIMA, Y. AND NAKA, K. 1985. Chromosomal polymorphisms in the Biwa Trout (Salmonidae) with an increase or decrease in constitutive heterochromatin. Proc. Japan. Acad., 61B, 483-485.

ZENZES, M. T. AND VOICULESCU, I. 1975. C-banding patterns in Salmo trutta, a species of tetraploid origin. Genetica, 45, 531-536. 